\title{
Advertising watchdog reverses earlier ban on Coco Pops adverts
}

Watchdog the Advertising Standards Authority (ASA) has reversed a previous decision $^{1}$ to ban an advert from Kellogg's promoting its Coco Pops Granola product.

The advert shown on a children's TV channel was for the company's Coco Pops Granola breakfast cereal which was classed as not being a high fat, sugar and salt (HFSS) product and not subject to advertising restrictions.

The Obesity Health Alliance (OHA) lodged a complaint earlier this year, arguing that although the product was not an HFSS, the advert had the effect of promoting Coco Pops cereal due to the use of branding and the character Coco the Monkey which is strongly associated with the original Coco Pops cereal.

The complaint was upheld, but on 21 November 2018, the ASA issued a new

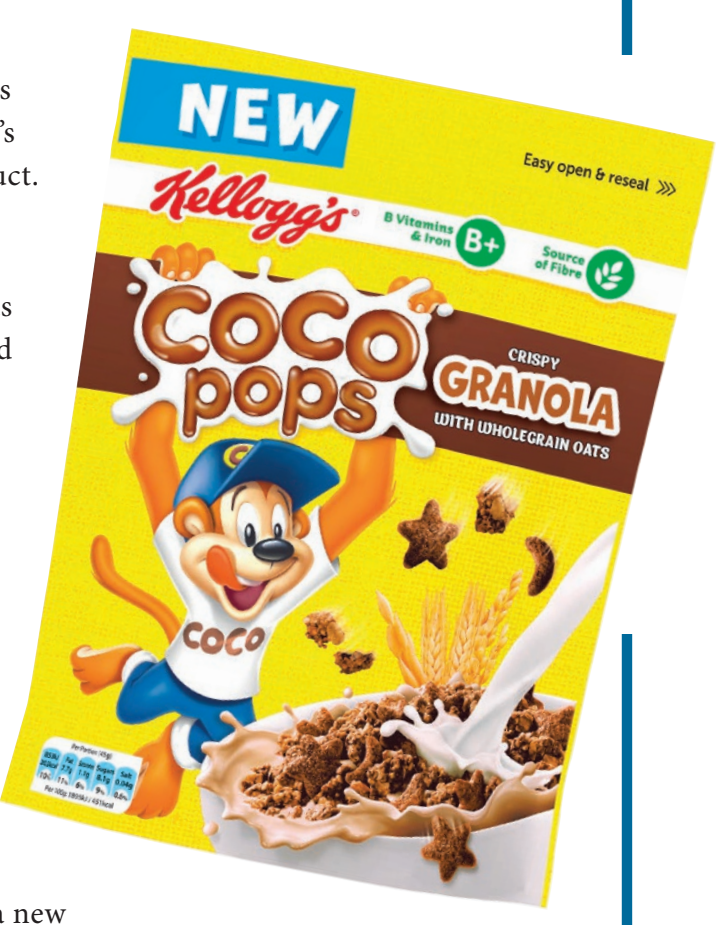
ruling ${ }^{2}$ which said: 'We therefore concluded that the ad was not an HFSS product ad for the purposes of the Code and was therefore not subject to the restrictions prohibiting HFSS product ads from being shown around children's programming.'

The OHA criticised the new decision, saying that the initial ruling had been an important decision that set a precedent for protecting children from junk food marketing.

Caroline Cerny, OHA Lead, said: 'These adverts are designed specifically to appeal to children with fun cartoon characters including the well-known Coco the Monkey and catchy jingles. The original ruling recognised the power of brand advertising and closed a loophole preventing food companies from advertising to children by using characters and music associated with their unhealthy products.

'Following a lobbying effort from Kellogg's, the industry funded regulator, the Advertising Standards Authority, has rowed back from their original decision. This is what happens when a large multi-national food company uses its legal weight to fight rulings that influence their profits. Sadly the price is the future health of our children. This is just another example of why we need strong Government action to protect children from unhealthy food marketing, starting with a $9 \mathrm{pm}$ watershed on junk food adverts on TV.'

A Kellogg's spokesperson said: 'We are pleased the advertising regulator has reversed its decision and ruled that this advert was not in breach of official rules.

'We felt the original judgement had potential unintended consequences for the industry and the positive intent of the regulations - acting as a disincentive for food companies like us to develop and launch better for you alternatives at a time when people are looking to our industry to take action.

1. BDJ. Regulator bans KFC and Kellogg's adverts from targeting children. Br Dent J 2018; 225: 282.

2. Advertising Standards Authority. ASA Ruling on Kellogg Marketing and Sales Company (UK) Ltd. 2018. Available at https://www.asa.org.uk/rulings/kellogg-marketing-and-sales-company--uk--ltd-a18-1.html (accessed November 2018) 